\title{
Heart-stopping action
}

\section{Some athletes diagnosed with a genetic heart condition are banned from competitive sport. Laura Spinney discovers how they are fighting for the right to run the risk of death.}

omenico Fioravanti won two gold medals at the Sydney Olympics in 2000 - for the men's 100-metre and 200metre breaststroke. But when he goes to Athens this year, it will be as a television commentator, not as a competitor.

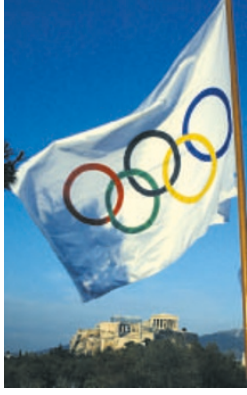
His fans will have seen him most recently in the reality TV show La Fattoria, or The Farm. In fact, he hasn't been in a swimming pool at all this year - though not by choice. In January, the 27-year-old Italian swimmer was diagnosed with an inherited heart condition called hypertrophic cardiomyopathy (HCM) and, under Italian law, he was forced to retire from competitive sport.

Fioravanti suffers from the same genetic problem that killed Cameroonian footballer Marc-Vivien Foé in June 2003 while he was playing in the Confederations Cup semi-final against Colombia, followed seven months later by Hungarian Miklos Feher, who died while playing for Portuguese football team Benfica. Both men died on the pitch - suddenly, and in front of the cameras. Even though Fioravanti knows he has the same condition and is well aware of the risks, his family is campaigning for a relaxation of the Italian law. They want him to keep on swimming - or at least to have the option.

$\mathrm{HCM}$ is the leading cause of sudden death in people under the age of 30. It is caused by the accumulation of an abnormal protein inside sarcomeres, which are a basic component of heart muscle cells. This causes the cells to grow too large and in a shambolic fashion, particularly around the left ventricle. As the muscles thicken, the heart can develop an irregular beat and runs the risk of stopping completely. About $0.1 \%$ to $0.2 \%$ of the world's population has HCM; each year, about $1 \%$ of these die ${ }^{1}$. The extra strain of excessive exercise is thought to trigger sudden death in people with the underlying condition ${ }^{2}$.

Doctors can diagnose HCM through imaging studies, treat it with drugs or surgery, and implant a defibrillator to kick-start the heart back into action should there be a major problem. But it is still difficult to assess the risk of sudden death in any given patient. Fioravanti's frustration stems from this final fact. To all appearances, his condition is mild. "At this point, I could state that he has a low probability of dying suddenly, even doing active sport," says Franco Cecchi, the cardiologist at the University of Florence who confirmed his diagnosis. Yet in Italy, the mere confirmation of the condition means that Fioravanti is banned from competitive sport.

Genetic testing is now gaining a foothold in studies of HCM, and holds the promise of sorting out this final detail. Fioravanti hopes that such tests may one day weed out those who have a high risk of suffering sudden death from those with a low risk, and so allow people like him to compete.

In Italy, uniquely, athletes are required by law to get an annual fitness certificate before being allowed to take part in any competitive event. As part of this assessment they are given an electrocardiogram (ECG) and questioned about their family history. If there is a suspicion of disease, they go on to have an echocardiogram ('echo') - an ultrasound scan of the heart and valves, which provides information about muscle thickness and the size of the heart's chambers. If this shows an abnormality, the ath-

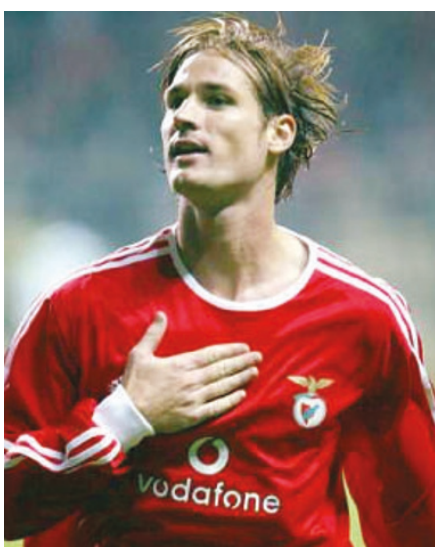

Miklos Feher (left) and Marc-Vivien Foé (pictured right) died on the field. lete is automatically disqualified - unless the sport is considered low risk, such as snooker or archery. If an athlete sneaks through the system and goes on to die while playing, the doctor who signed the authorizing certificate can be held liable if found negligent.

\section{Protect and survive}

The Italian system seems to prevent instances of sudden death among athletes, says Cecchi. In 1998, Domenico Corrado, a cardiologist at the University of Padua, and his colleagues carried out a survey of people screened for the condition between 1979 and 1996. Of some 34,000 hopeful athletes, 22 had HCM and were disqualified from competitive sport. Only one athlete, who slipped through the tests, subsequently died of $\mathrm{HCM}^{3}$
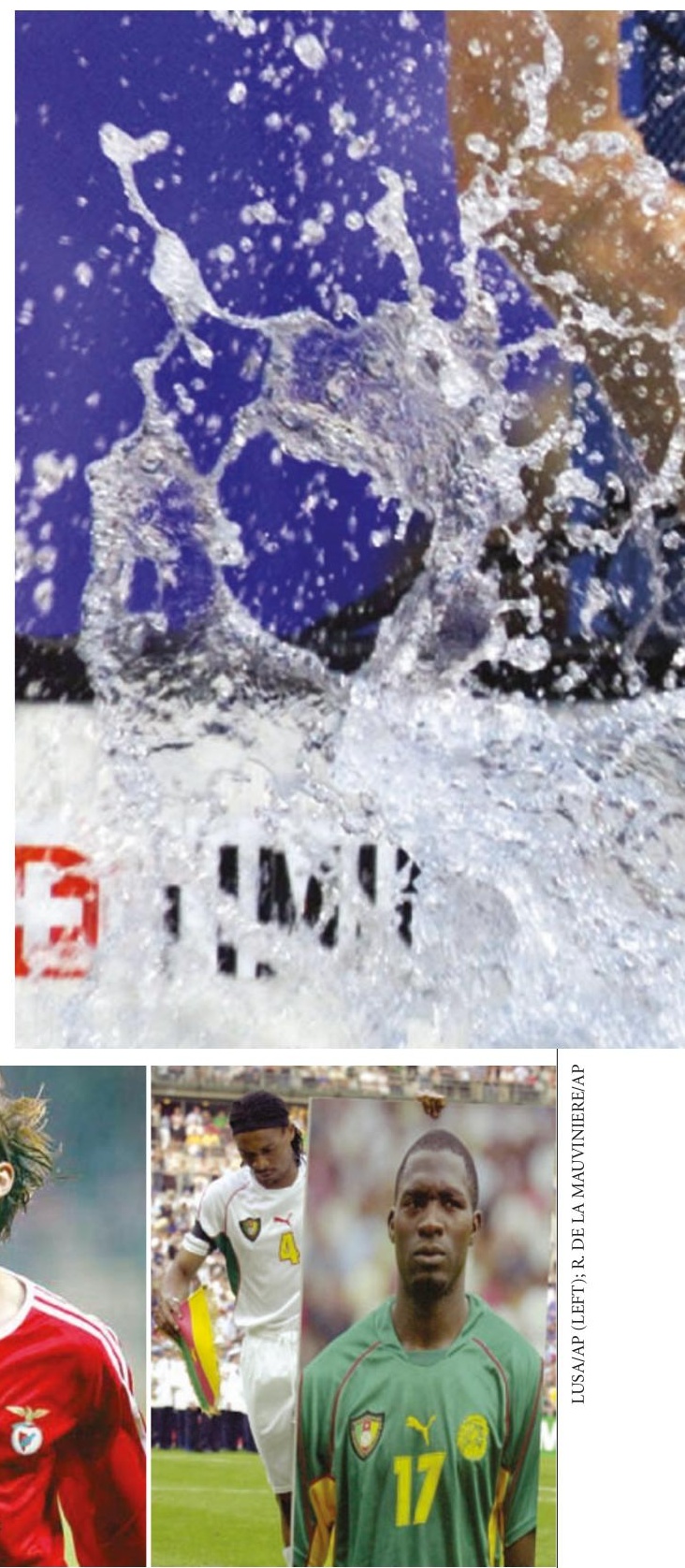

Cecchi admits that the system has its flaws. Corrado's team showed that screening is less efficient at detecting another potentially lethal heart abnormality called arrhythmogenic right ventricular cardiomyopathy. And it may be over-protective, banning people such as Fioravanti who could probably safely swim on. Nevertheless, the rate of sudden deaths among Italian athletes has been steadily decreasing, says Cecchi.

In the single case that escaped the screening net in Corrado's study, the clinical diagnosis was uncertain. Diagnosis of HCM is often not clear-cut, partly because exercise causes non-harmful changes to an athlete's heart muscle that can be mistaken for a sign of HCM. Some of this confusion might be avoided if a genetic test existed that could pinpoint the 200 or so mutations that have, 


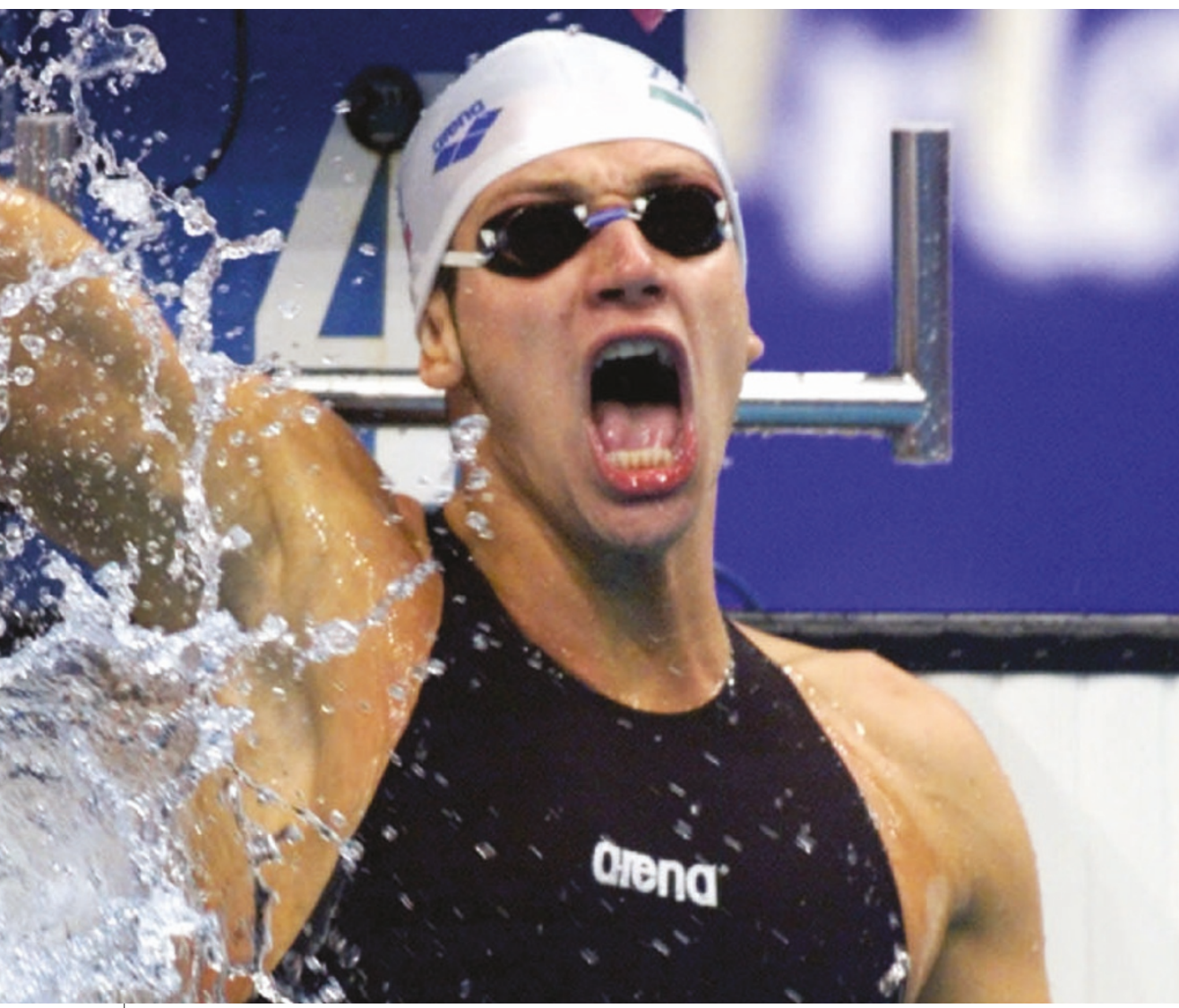

Dicing with death: Domenico Fioravanti has two gold medals - and a genetic condition that has led him to be banned from competitive sport.

to date, been linked with the condition.

These mutations occur in 12 genes, all of which code for the sarcomeric proteins in heart muscle ${ }^{4}$. So far, genetic testing for HCM in Europe and the United States has been available only to individuals with a high risk of having HCM, and then only under the auspices of research programmes. But the first commercial test went on sale this May in the United States. Designed by Jonathan and Christine Seidman of the genetics department at Harvard Medical School in Boston, Massachusetts, the test is based on detecting mutations in eight genes that the couple think account for $75 \%$ of cases of HCM.

\section{On the right track?}

Barry Maron, director of the Minneapolis Heart Institute Foundation, has serious doubts about the usefulness of this genetic test for diagnosis. It misses not only $25 \%$ of the genes already linked to the condition, he says, but also the many other genetic mutations that are probably involved but have not yet been discovered. Even if a comprehensive test were available, he says, cost would prohibit its use for young athletes.

The Seidmans admit that the price tag of US $\$ 3,000$ means their test may not be feasible for screening the vast population of young athletes. Even ECG and echo tests are currently considered too expensive for many.
"But it might be worth considering for the considerably smaller population of Olympic athletes," says Christine Seidman.

Yet it remains unclear how these genetic mutations affect risk. At the University of Florence, Cecchi's team is studying some 350 patients and their families in an attempt to work out how, and to what degree, each of the HCM-related genes predisposes patients to sudden death. So far their work remains inconclusive ${ }^{5}$.

Even if the issue of diagnosis can be cracked, it still leaves pol-

icy-makers and athletes with the dilemma of what to do with the information. One case frequently discussed by doctors concerned about this issue is that of Nicholas Knapp. A talented 17-year-old basketball player, Knapp had already been offered a sports scholarship at Northwestern University, Illinois, when his heart stopped at the end of a game in 1994. He was resuscitated, diagnosed with HCM and surgically implanted with a defibrillator. Nevertheless, he accepted the sports scholarship. The university allowed him to keep the scholarship, but barred him from playing intercollegiate

A lengthy court battle ensued, in which Knapp argued that the choice was his, even if by playing he risked death. Northwestern's decision was eventually upheld, but Knapp was free to enrol in another university's basketball programme, and did so. Three years after his first cardiac arrest, he suffered an basketball on medical grounds. episode of tachyarrhythmia - an abnormally fast and irregular heartbeat. His defibrillator discharged, probably preventing a second arrest and saving his life.

Since Knapp's case, it has been hard for athletes with a known condition to play competitively in the United States. But, ten years on, there are still no formal laws to govern these decisions, only guidelines. HCM patients had to wait until this June for a guide ${ }^{6}$ on participating in recreational sport. The American Heart Association recommends that people avoid 'burst' activities such as sprinting, and rates the advisability of different sports for people with different conditions. Swimming is listed as "probably permitted" for HCM patients - although this is not meant to apply to athletes at the Olympiclevel.

\section{Tough love}

Maron, who helped to write these recommendations, says he thinks that the decision about whether a person with HCM can participate in sport should be taken out of the athlete's hands. "You can't just hand out freedoms against medical advice," he says. His own research shows that the median age of HCM sufferers who die while engaged in sport is very young - just 17 years old.

In the United Kingdom, William McKenna, a cardiologist at University College London, describes the situation as "shambolic". Athletes are not routinely checked for HCM. And when a sudden death occurs, he says, relatives are rarely informed about the victim's genetic condition or the possible risk to themselves. Earlier this year the UK government agreed to establish new guidelines on handling cases of sudden death. But the guidelines are likely to steer clear of any recommendations about screening or advice for young athletes.

While various countries battle with the ethical issues, the science marches on. If genetic tests become more conclusive, and heart scans cheaper, then at least we will have a better chance of diagnosing risk. But that is a distant hope for Fioravanti, who says he has resigned himself to the premature end of his career. He considered going to live in another country where he could continue to swim, but decided he would suffer too much away from home. So after the closing ceremony of this year's Olympic Games, he will begin building his new career — as a trainer, rather than a swimmer.

Laura Spinney is a freelance writer based in London.

\footnotetext{
1. Maron, B. J. Circulation 106, 2419-2421 (2002).

2. Corrado, D., Basso, C., Rizzoli, G., Schiavon, M. \& Thiene, G. J. Am. Coll. Cardiol. 42, 1964-1966 (2003).

3. Corrado, D., Basso, C., Schiavon, M. \& Thiene, G. N. Engl. J. Med. 339, 364-369 (1998).

4. Morita, H. et al. Cold Spring Harb. Symp. Quant. Biol. 67, 383-388 (2002).

Torricelli, F. et al. Am. J. Cardiol. 92, 1358-1362 (2003). 6. Maron, B. J. et al. Circulation 109, 2807-2816 (2004).
} 